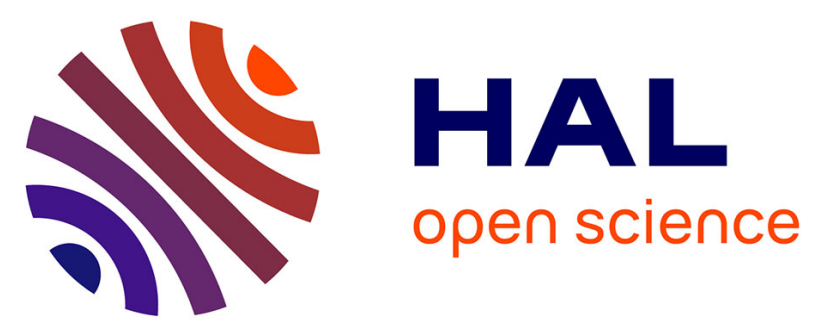

\title{
INFLUENCE OF H2 PARTIAL PRESSURE ON THE MORPHOLOGY AND CRYSTALLIZATION OF SiC LAYERS OBTAINED BY LPCVD USING TETRAMETHYLSILANE
}

\author{
A. Figueras, R. Rodriguez-Clemente, S. Garelik, J. Santiso, B . Armas, C. \\ Combescure, Annie Mazel, Yolande Kihn, Jean Sévely
}

\section{To cite this version:}

A. Figueras, R. Rodriguez-Clemente, S. Garelik, J. Santiso, B . Armas, et al.. INFLUENCE OF H2 PARTIAL PRESSURE ON THE MORPHOLOGY AND CRYSTALLIZATION OF SiC LAYERS OBTAINED BY LPCVD USING TETRAMETHYLSILANE. Journal de Physique IV Proceedings, 1991, 02 (C2), pp.C2-225-C2-232. 10.1051/jp4:1991228 . jpa-00249815

\section{HAL Id: jpa-00249815 https://hal.science/jpa-00249815}

Submitted on 1 Jan 1991

HAL is a multi-disciplinary open access archive for the deposit and dissemination of scientific research documents, whether they are published or not. The documents may come from teaching and research institutions in France or abroad, or from public or private research centers.
L'archive ouverte pluridisciplinaire HAL, est destinée au dépôt et à la diffusion de documents scientifiques de niveau recherche, publiés ou non, émanant des établissements d'enseignement et de recherche français ou étrangers, des laboratoires publics ou privés. 
Colloque C2, suppl. au Journal de Physique II, Vo1. 1, septembre 1991

INFLUENCE OF $H_{2}$ PARTIAL PRESSURE ON THE MORPHOLOGY AND CRYSTALLIZATION OF SIC LAYERS OBTAINED BY LPCVD USING TETRAMETHYLSILANE

Abstract

A. FIGUERAS*, R. RODRIGUEZ-CLEMENTE* ${ }^{*}$, S. GARELIK* , J. SANTISO*,

B. ARMAS**, C. COMBESCURE**, A. MAZEL**, Y. KIHN"** and

J. SEVELY**

* ICMAB-CSIC, Campus UAB, SP-08193 Bellaterra, Barcelona, Spain

* IMP-CNRS, BP 5, F66520 Font Romeu, France

* * CEMES-LOE, CNRS, 29 rue J. Marvig, BP 4347.

F-31055 Toulouse Cedex, France

Silicon carbide layers have been produced by Chemical Vapor Deposition at low pressures (LPCVD) on graphite substrates from tetramethylsilane and hydrogen. The effects of change in partial pressure of hydrogen on the kinetics, morphology and structure of the layers have been examined. A model of the layer growth is developed.

\section{1.- INTRODUCTION}

Silicon carbide coatings obtained by Chemical Vapor Deposition (CVD) have been extensively studied because of their high mechanical and chemical performances. Their outstanding properties, such as high chemical stability at high temperatures, high thermal shock resistance, hardness and resistance to wear, have attracted considerable interest in several fields of science and technology.

In previous studies the kinetics and morphology of SiC layers obtained by CVD using tetramethylsilane (TMS) as precursor and hydrogen as carrier gas have been investigated. The importance of the presence of hydrogen on the growth of $\mathrm{SiC}$ layers has also been reported /1/. The present work concerns the study of the effect of hydrogen on the kinetics, morphology and structure of SiC layers deposited on graphite substrates from TMS decomposition.

\section{2.- EXPERIMENTAL}

$\mathrm{SiC}$ layers were deposited on polycrystalline graphite substrates in a vertical cold-wall CVD reactor, using tetramethylsilane and $\mathrm{H}_{2}$ as precursor and carrier gas respectively. The gas flows were controlled by mass flowcontrollers. The TMS container was maintained at room temperature. Substrates were heated by RF (Radio Frequency) induction and the temperature was measured by an optical pyrometer placed perpendicularly to the geometrical axis of the deposition system.

The experiments were performed under reduced pressure conditions. The pressure in the reaction chamber was regulated by using a valve connected to the vacuum system. The mass 
The experiments were performed at fixed substrate temperature $T_{S}=1300^{\circ} \mathrm{C}$. The influence of $\mathrm{H}_{2}$ in the growth process was studied by changing the hydrogen partial pressure $\left(\mathrm{P}_{\mathrm{H}_{2}}\right)$ from 0 to $107 \mathrm{hPa}$; fluxes were ranged from 0 to $120 \mathrm{Ncm}^{3} / \mathrm{min}$. The total pressure $\left(\mathrm{P}_{\mathrm{T}}\right)$ in the reactor was varied in order to maintain the TMS partial pressure (PTMS) constant at $13 \mathrm{hPa}$ for all the experiments (flow of $15 \mathrm{Ncm}^{3} / \mathrm{min}$ ). The gas velocity was the same for all the deposition runs.

After a deposition run, the layer thickness was about $60 \mu \mathrm{m}$ in all cases. Morphological characterization of the layers was performed by using a scanning electron microscope while crystallographic information was obtained by standard powder X-ray diffraction. In order to determine the effect of the hydrogen partial pressure on the growth of $\mathrm{SiC}$ at a submicron scale, the microstructure of the layers was also investigated by transmission electron microscopy (TEM). Chemical analysis was performed by electron energy loss spectroscopy (EELS).

\section{3.- RESULTS}

3-1 - Effect of $\mathrm{H}_{2}$ partial pressure on the deposition kinetics and the morphology of the layers

The dependence of the $\mathrm{SiC}$ film deposition rate (J) on $\mathrm{P}_{\mathrm{H}_{2}}$ at constant $\mathrm{P}_{\mathrm{TMS}}$ has three well defined regimes (Figure 1). The first one, in the $\mathrm{P}_{\mathrm{H} 2}$ range $0-10 \mathrm{hPa}$, shows an increase of $\mathrm{J}$ with $\mathrm{P}_{\mathrm{H}_{2}}$. In the two following zones, 10 to $80 \mathrm{hPa}$ and 80 to $107 \mathrm{hPa}, \mathrm{J}$ decreases with $\mathrm{P}_{\mathrm{H}_{2}}$, this variation being faster for $\mathrm{P}_{\mathrm{H}_{2}}$ greater than $80 \mathrm{hPa}$. In these two latter cases, an apparent dependence of a $\mathrm{P}_{\mathrm{T}}^{-1 / 2}$ law was found.

In the $0-30 \mathrm{hPa} \mathrm{H}_{2}$ pressure range, the introduction of $\mathrm{H}_{2}$ enhances $\mathrm{J}$ which is always higher than $\mathrm{J}_{0}$, the deposition rate without $\mathrm{H}_{2}$. Above $30 \mathrm{hPa}$, the deposition rate $\mathrm{J}$ diminishes monotonically and remains lower than $\mathrm{J}_{0}$.

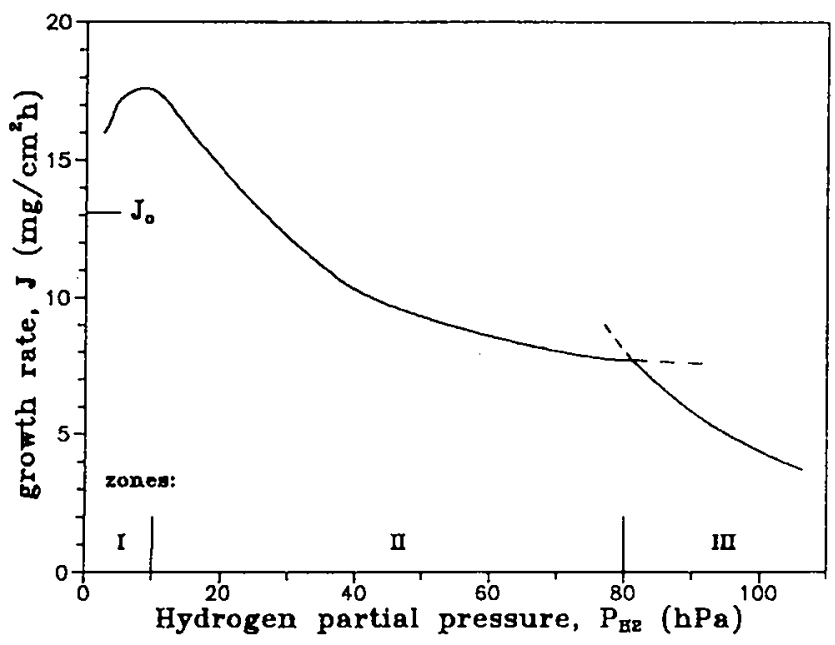

Figure 1 : Dependence of the growth rate $\mathrm{J}$ on the hydrogen partial pressure. 
a)

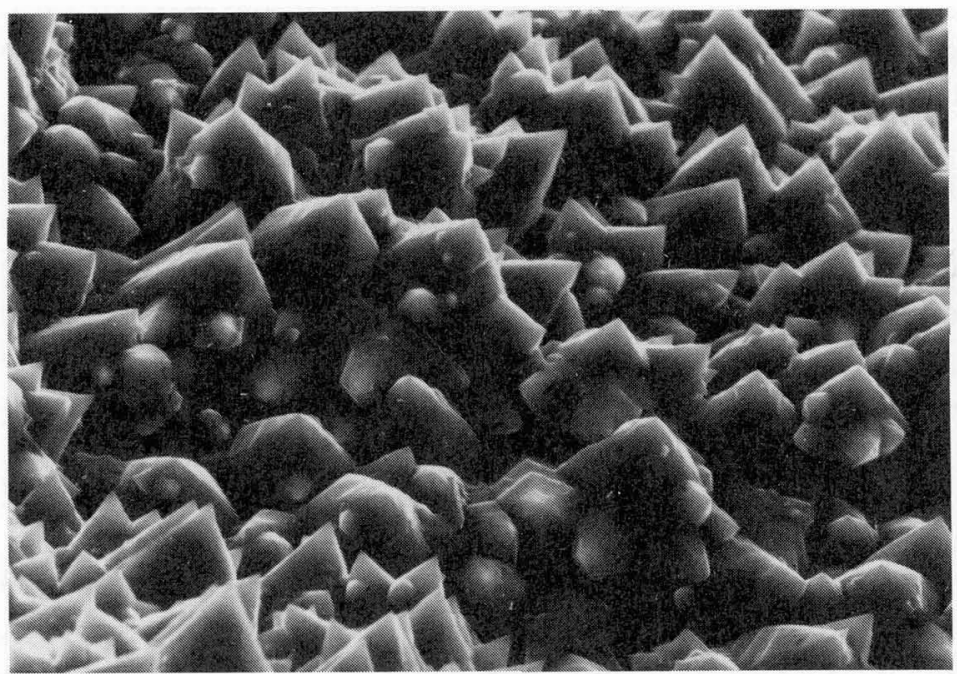

b)

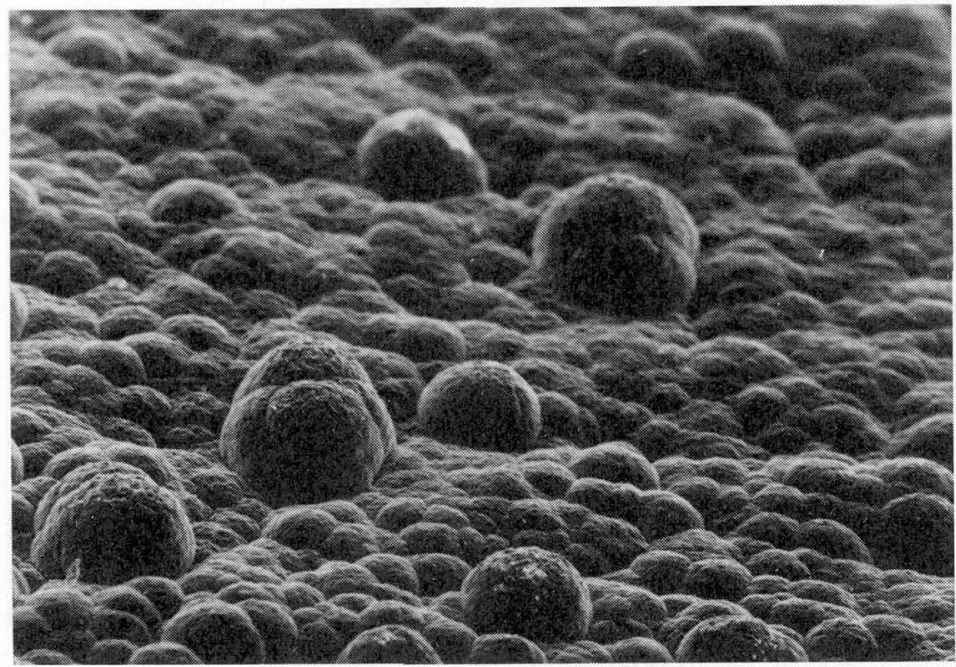

Figure 2 : SEM micrographs of the layers obtained at :

a) $\mathrm{PH}_{2}=0 \mathrm{hPa}, \times 3000$, b) $\mathrm{PH}_{2}=107 \mathrm{hPa}, \times 200$ 
The deposited layers have been observed with a Scanning Electron Microscope and Figure 2 shows the evolution of the morphology as a function of $\mathrm{P}_{\mathrm{H}_{2}}$. Two kinds of morphologies have been found : facetted structures (Figure $2 \mathrm{a}, \mathrm{P}_{\mathrm{H}_{2}}=0$ ) and aggregates with defined borders (Figure $2 \mathrm{~b}, \mathrm{P}_{\mathrm{H}_{2}}=107 \mathrm{hPa}$ ). Generally, the first kind of morphology is obtained for $\mathrm{P}_{\mathrm{H}_{2}}$ lower than $30 \mathrm{hPa}$ and the second one above this value. In all the experiments the layers were homogeneous, and were identified by $\mathrm{X}$-ray powder diffraction as $\mathrm{SiC}$ without crystallized $\mathrm{Si}$ or C. Chemical microanalysis performed by EELS has confirmed that, in all cases, the material is stoichiometric (Figure 3). An atomic ratio $\mathrm{Si} / \mathrm{C}=1$ with a few percent accuracy has been obtained by the measurements of the areas $S$ between the background fitting curves (dotted lines) and the experimental distributions (full lines) in a $100 \mathrm{eV}$ energy loss window after the edges. The classical quantitative analysis formula : $\mathrm{N}_{\mathrm{x}} / \mathrm{N}_{\mathrm{y}}=\mathrm{S}_{\mathrm{x}} / \mathrm{S}_{\mathrm{y}} \cdot \sigma_{\mathrm{y}} / \sigma_{\mathrm{x}}$, where $\sigma$ represent the partial cross sections evaluated in a $100 \mathrm{eV}$ energy window, has been used $/ 2 /$.

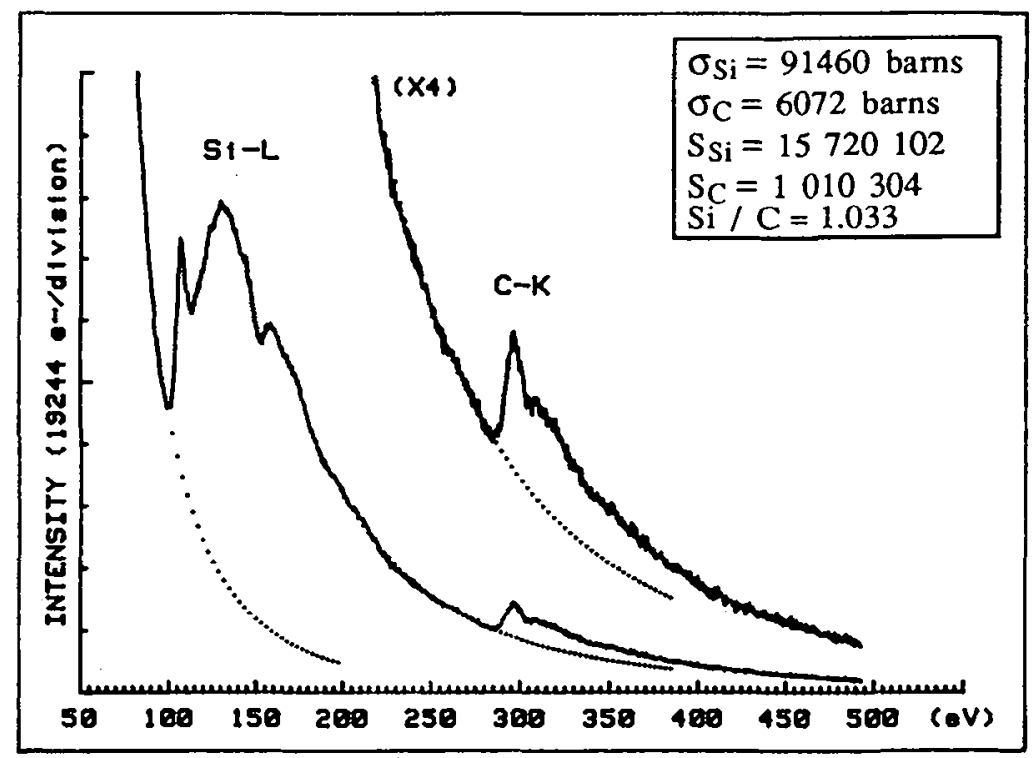

Figure 3 : Example of electron energy loss spectrum corresponding to silicon carbide at $\mathrm{PH}_{2}=0 \mathrm{hPa}$. Primary energy : $120 \mathrm{keV}$; collection angle : $9 \mathrm{mrd}$.

3-2 - Effect of $\mathrm{H}_{2}$ partial pressure on the crystallization

The diffractograms of layers obtained at different $\mathrm{PH}_{2}$ values are shown in Figure 4. They exhibit two main peaks which correspond to distances between crystalline planes of $0.251 \mathrm{~nm}$ and $0.154 \mathrm{~nm}$. These peaks could be attributed to the (111) and (220) reflections if the $\beta-\mathrm{SiC}$ cubic structure is assumed for the deposited layers.

The ratio $\alpha$ of the intensities of these two peaks shows a strong variation when $\mathrm{P}_{2}$ increases. The highest value : $\alpha=15.4$ is obtained for $\mathrm{P}_{2}=0$ (Figure 4a). This ratio decreases slightly when $\mathrm{PH}_{2}$ increases up to $30 \mathrm{hPa}$. Above this pressure $\alpha$ strongly decreases : $\alpha=2.46$ for $\mathrm{PH}_{2}=53 \mathrm{hPa}$ (Figure 4b) and $\alpha=0.086$ for $\mathrm{P}_{2}=107 \mathrm{hPa}$ (Figure 4c). 
This variation is indicative of structural and orientational changes of the deposited layers as confirmed by TEM observations.

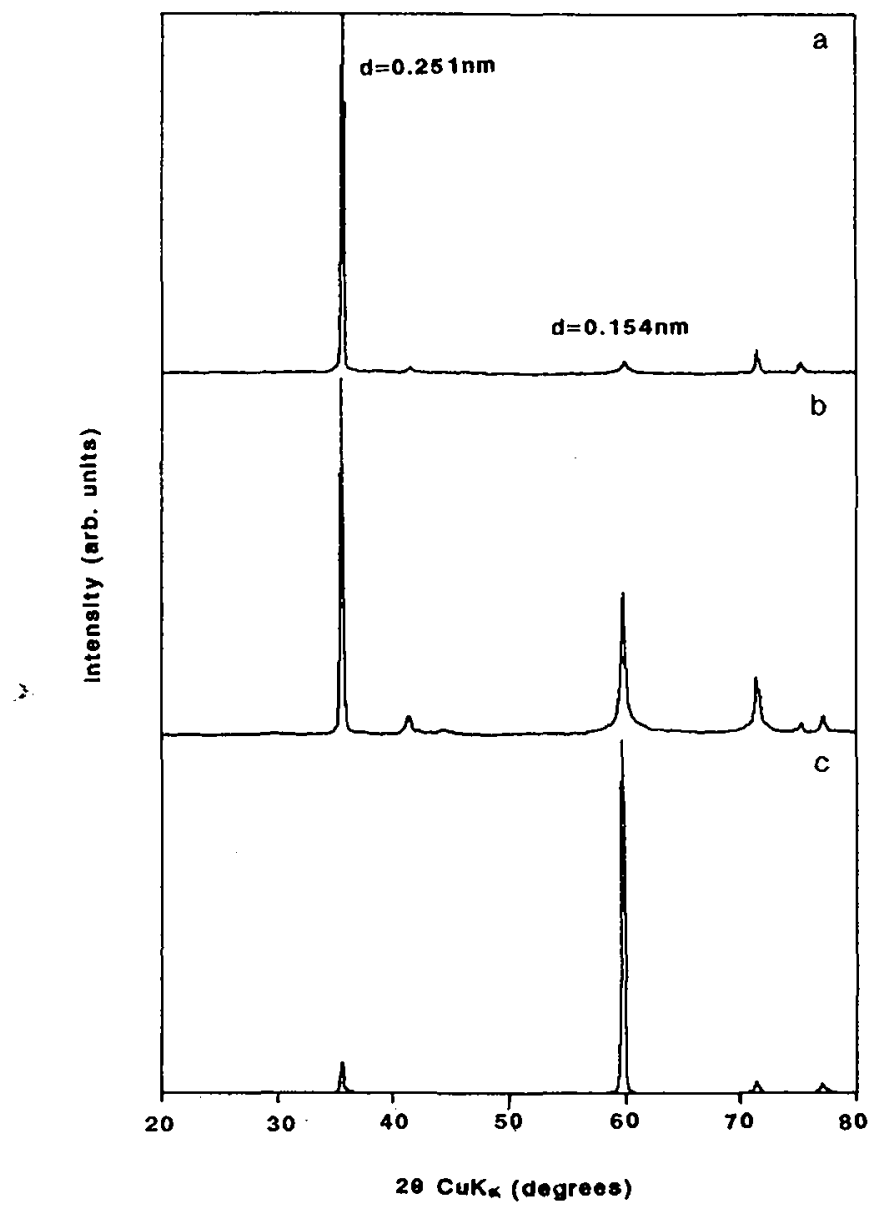

Figure $4: \mathrm{X}$-ray diffraction patterns of the layers obtained at :

a) $\mathrm{P}_{\mathrm{H}_{2}}=0 \mathrm{hPa}$, b) $\mathrm{P}_{\mathrm{H}_{2}}=53 \mathrm{hPa}$, c) $\mathrm{P}_{\mathrm{H}_{2}}=107 \mathrm{hPa}$

The study by transmission electron microscopy of a layer grown at $\mathbf{P}_{\mathrm{H}_{2}}=0 \mathrm{hPa}$ has revealed that the structure of $\mathrm{SiC}$ is not a zincblende structure but corresponds to a "one-dimensionallydisordered" polytype as already reported for SiC-CVI layers $13 /$. The continuous streaking of reflections observed on the electron diffraction pattern reproduced in Figure $5 \mathrm{a}$ does indeed indicate that this material is constituted by a disordered stacking along the growing direction of the Si-C elementary layers. The arrowed strong diffraction spot corresponds to the $0.251 \mathrm{~nm}$ distance separating these layers. The dark field image obtained by selecting this spot allows the disordered arrangement of the layers to be clearly observed. This result is in good agreement with the X-ray diffractogram of Figure 4a showing a predominant reflection associated with the periodicity of $0.251 \mathrm{~nm}$ 


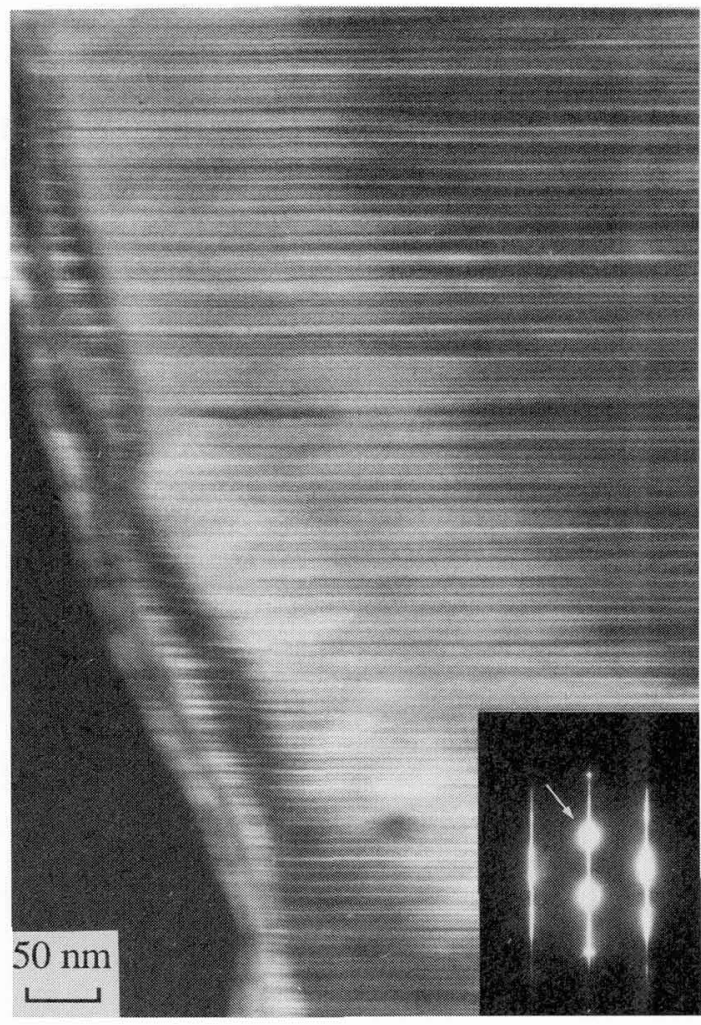

a)

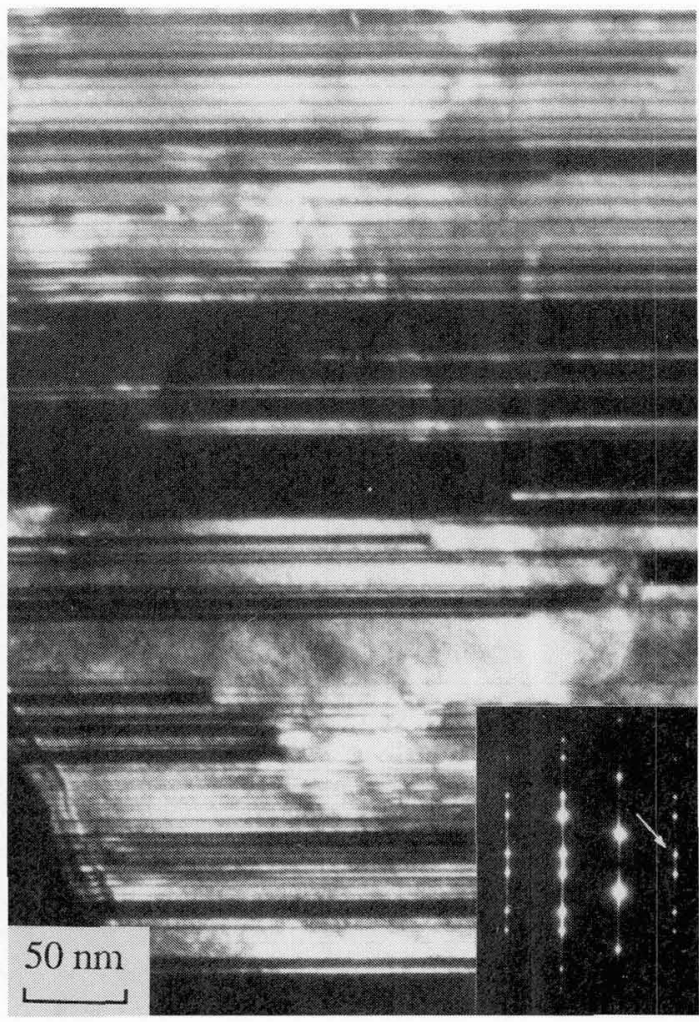

b)

Figure 5 : Dark field transmission electron microscopy images and corresponding diffraction patterns of $\mathrm{SiC}$ layers prepared with different hydrogen partial pressure :

$$
\text { a) } \mathrm{P}_{\mathrm{H}_{2}}=0 \mathrm{hPa} \text {, b) } \mathrm{P}_{\mathrm{H}_{2}}=107 \mathrm{hPa}
$$

In the same way, the TEM observation of a layer obtained at $\mathrm{P}_{\mathrm{H}_{2}}=107 \mathrm{hPa}$ has demonstrated that, in this case, the material is a heavily twinned $\beta-\mathrm{SiC}$ (Figure $5 \mathrm{~b}$ ). The electron diffraction pattern reproduced in this figure corresponds to a [011] incident beam direction and a [11 $\overline{1}$ ] twin axis. The dark field image associated with the arrowed reflection clearly reveals the distribution of twins in the specimen.

\section{4.- DISCUSSION}

The effect of the introduction of $\mathrm{H}_{2}$ as carrier gas in the growth of $\mathrm{SiC}$ using tetramethylsilane has been studied /1/. These previous results show that the deposition of SiC from TMS at the working temperature is a diffusion controlled process. The pyrolysis reaction forming the growth units is catalyzed by the hydrogen, yielding a strong reduction of the apparent activation energy. This fact explains the sudden increase of the deposition rate, J, when a $\mathrm{H}_{2}$ partial pressure is introduced in the reaction chamber, as shown on the first zone of Figure 1. 
In this regime, the growth of the layer is columnar and the external morphology is formed by facetted structures showing a stacking of laminae parallel to the substrate surface. This morphology is nearly the same as that observed for the layers obtained at $\mathrm{P}_{\mathrm{H}_{2}}=0$.

When $\mathrm{PH}_{2}$ is over $10 \mathrm{hPa}$, at constant gas velocity, a decrease of the deposition rate is observed. This fact could be explained by the dependence of the gaseous species diffusion coefficient on the total pressure according to a $\mathrm{P}_{\mathrm{T}}{ }^{-1 / 2}$ law $/ 4 /$. However, this mechanism is not sufficient to explain the curve breakpoint which appears at $\mathrm{P}_{\mathrm{H}_{2}}=80 \mathrm{hPa}$ and the different slopes and types of crystallization observed in the second and third regimes.

In the second zone, the crystalline planes having a $0.251 \mathrm{~nm}$ interplanar distance, designated as $F$ faces, are saturated by hydrogen and the pyrolysis reaction leads to a maximum and constant growth rate. Furthermore, the crystalline planes related to the $0.154 \mathrm{~nm}$ distance, designated as $\mathrm{S}$ planes, are not completely saturated and their growth rate increases with increasing $\mathrm{P}_{\mathrm{H}_{2}}$ but remains lower than that of $\mathrm{F}$ faces in this $\mathrm{P}_{2}$ range. Consequently, the $\mathrm{X}$-ray diffractogram exhibits a dominant reflection corresponding to the $0.251 \mathrm{~nm}$ periodicity and the ratio $\alpha$ previously defined ( $\$ 3.2$ ) slightly decreases as observed.

In the third regime, the $\mathrm{S}$ faces are saturated by hydrogen. The pyrolysis reaction leads, in this case, to a maximum and constant growth rate of these planes which becomes higher than the growth rate of the $\mathrm{F}$ faces, already constant in this range of $\mathrm{P}_{\mathrm{H}_{2}}$. The $\mathrm{X}$-ray intensity reflection associated with the $0.154 \mathrm{~nm}$ periodicity now becomes dominant and the $\alpha$ coefficient strongly decreases. In this zone, the growth tends to be columnar due to the geometrical competition of the neighbouring growing crystallites. The external morphology is different from that obtained at lower $\mathrm{P}_{2}$ (Figure 2b) showing that there are no facetted structures due to the $\mathrm{H}_{2}$ adsorption effect, which hinders the development of regular morphologies.

In all cases, the resulting growth is dominated by the variation of the diffusion coefficient with the total pressure.

\section{CONCLUSIONS}

1.- The introduction of hydrogen in the reaction chamber as carrier gas enhances the deposition rate of $\mathrm{SiC}$. This trend is maintained up to $\mathrm{P}_{\mathrm{H}_{2}}=10 \mathrm{hPa}$ for $\mathrm{P}_{\mathrm{TMS}}=13 \mathrm{hPa}$, defining a first regime. Above this value, the deposition rate, $\mathrm{J}$, decreases with increasing $\mathrm{P}_{\mathrm{H}_{2}}$ and two other regimes have been found due to the anisotropy in the reactivity of the crystal surfaces. In both these cases, $\mathrm{J}$ is diffusion controlled. The variations of $\mathrm{J}$ with $\mathrm{P}_{\mathrm{H}_{2}}$ cannot be related to gas velocity changes because all the experiments were carried out at constant gas velocity.

2.- The structure of the layers obtained at low hydrogen partial pressures corresponds to "one-dimensionally-disordered" polytypes, consisting of stacks of Si-C elementary layers spaced by $0.251 \mathrm{~nm}$.

3.- The increase in hydrogen partial pressure leads to the growth of layers whose structure progressively tends to that of cubic $\beta-\mathrm{SiC}$. In this case, the layers $0.251 \mathrm{~nm}$ apart correspond to the (111) planes. 


\section{REFERENCES}

/1/ FIGUERAS A., GARELIK S., RODRIGUEZ-CLEMENTE R., ARMAS B., COMBESCURE C., DUPUY C. J. Cryst. Growth, in press.

12/ EGERTON R. F.Electron Energy Loss Spectroscopy in the Electron Microscope, Plenum Press, New York (1986).

B/ SCHAMM S., MAZEL A., DORIGNAC D., SEVELY J. Microsc. Microanal. Microstruct. $\mathrm{N}^{\circ} 2$ (1991).

14/ BLOEM J., GILLING L. J. Current Topics in Material Science, Vol.1, Ed. by E. Kaldis, North-Holland, Amsterdam (1978) 147. 